\title{
GÊNERO E RELIGIÃO SOB A ÓTICA DA REDESCRIÇÃO
}

\author{
Gender and Religion in the Perspective of Redescription
}

El Género y la Religión en la Perspectiva de la Redescripción

MARIa JOSÉ PEREIRA Rocha

\begin{abstract}
Resumo: O principal propósito deste artigo é analisar como se manifesta a relação entre gênero e religião. Nessa medida, o texto opta por uma reflexão singular elaborada sob a ótica do neopragmatismo como teoria ad hoc, entendida como corrente filosófica que privilegia a conversação. O texto explora como eixo de análise a noção de redescrição como tarefa da imaginação. É com imaginação que descrevemos a nós e aos outros. Com base nessa compreensão enfatiza-se elementos que possibilitam repensar gênero e religião levando-se em conta a redescrição de Rorty. A tentativa é a de escrever, contar e recontar uma história sobre essas duas categorias de uma outra forma. Portanto, o esforço é o de refletir sobre gênero e religião com base em dois eixos: o primeiro se estabelece através da análise da noção de gênero e da noção de religião. O segundo baseia-se em fragmentos de falas de algumas pessoas que expressaram o seu entendimento em relação a essas categorias.
\end{abstract}

Palavras-chave: Gênero; Religião; Redescrição.

\begin{abstract}
The main goal of this article is to analyze how manifest the relation between gender and religion. In that measure, the text opts for a singular reflection elaborated under the optic of the neopragmatism as theory ad hoc, understood as philosophical current that privileges the conversation. The text explores as analysis axis the notion of the redescribe as task of the imagination. It is with imagination that we describe to us and to the others. With the Base in that understanding emphasize elements that make possible rethink gender and religion being taken into account the redescription of Rorty. The attempt is the writing, to tell and to retell a story about those two categories in another way. Therefore, the effort is to contemplate about gender and religion with the base in two axes: the first settles through the analysis of the gender notion and of the of religion notion. The second base about fragments of some peoples speaking that expressed their understanding in relation to those categories.
\end{abstract}

Keywords: Gender; Religion; Redescription.

Resumen: El objetivo principal de este artículo es examinar la manera como si manifesta la relación entre el género y la religión. Por lo tanto, el texto opta por una reflexión singular desarrollada desde la perspectiva de neopragmatismo como la teoría ad hoc, entendida como corriente filosófica que privilegia la conversación. El texto explora como eje de análisis, la noción de redescripción como la tarea de la imaginación. Es con la imaginación que describimos a nosotros mismos y los demás. Sobre la base de este entendimiento se hace hincapié en los elementos que permiten repensar el género y la religión teniendo en cuenta la Redescripción de Rorty. El intento es escribir, contar y recontar una historia sobre estas dos categorías de otra forma. Por lo tanto, el esfuerzo es para reflexionar sobre el género y la religión basada en dos ejes: el primero se establece mediante el análisis del concepto de género y el concepto de religión. El segundo se basa en fragmentos del discurso de algunas personas que expresaron su entendimiento en relación con esas categorías.

Palabras-clave: Gênero; Religión; Redescripción.

Quando aceitei a tarefa de fazer um texto sobre gênero e religião tomando por base a perspectiva da redescrição sabia das dificuldades que ia encontrar. Consciente dos obstáculos e da necessidade de reflexão sobre a temática, encarei o desafio procurando elementos e caminhos que facilitassem adentrar-me a esse campo de estudo.

A tarefa de escrever sobre gênero e religião implica certos riscos e ao mesmo tempo permite inúmeras interrogações: por exemplo, qual é o eixo mais adequado para explicar essas noções e suas interfaces? Como abordar a temática de forma criativa? Que metodologia deve ser adotada na construção do texto? É instigante, no entanto, pensar que esse exercício de elaboração deve apresentar uma vertente, um aspecto ou um olhar novo em relação à produção realizada nos últimos tempos. Nesse sentido, experimentou-se grande dificuldade para encontrar o fio condutor desta análise. Uma música, uma frase, uma poesia, um filme, um livro, um texto, uma narrativa: tudo poderia desatar o nó e servir de linha para costurar uma nova abordagem sobre este assunto.

Perdida em pensamentos tornou-se possível resgatar uma passagem especial de Ghiraldelli Jr. (1999, p. 49) sobre a redescrição na qual esse autor cita um argumento de Rorty que afirma: "Todas as descrições que temos das ações são descrições adequadas aos nossos propósitos”. Esse era o link que faltava para conduzir a reflexão e adotar a teoria da redescrição como uma tarefa da imaginação. É com imaginação que descrevemos a nós e aos outros. Esse entendimento significa adotar a seguinte idéia: o que há na mão é a linguagem para contar histó- 
rias capazes de convencer as pessoas a serem melhores (Ghiraldelli Jr., 2003, p. 179).

No que se refere ao argumento da redescrição, o filme Nem gravata, Nem honra (Brasil/2001), do diretor Marcelo Masagão, inspira uma analogia baseada na sua metodologia de montagem. Tomá-la como instrumento para iniciar a discussão sobre gênero e religião permite uma aposta em nova modalidade de reflexão acerca dessa temática. O referido filme é uma obra de ação e romance que discute as diferenças entre homens e mulheres na pequena cidade de Cunha. $\mathrm{O}$ diretor e sua equipe realizam um documentário, entrevistam os habitantes da região perguntando qual é a diferença existente entre mulheres e homens. As pessoas respondem as indagações levando-se em conta o local em que vivenciam esses papéis masculino e feminino no cotidiano. Por isso, esse filme é um instrumento que pode levar uma a possibilidade de análise dessas duas categorias. Não se pretende aqui fazer um documentário, mas basear-se no já existente para enfrentar essa reflexão. Dessa perspectiva, pode-se perguntar acerca da concepção de gênero e religião que algumas pessoas têm, de forma aleatória, sem preocupação com a delimitação de um universo, de uma amostra e de outras coisas mais. Pode-se usar os relatos como uma redescrição adequada aos propósitos deste ensaio, mais precisamente, elaborar uma análise sobre gênero e religião. A forma como o diretor de Nem gravata, Nem honra conduz a narrativa sobre a diferença entre homens e mulheres, propicia uma saída para abordar o tema de forma semelhante optando-se por utilizar fragmentos de opiniões de pessoas como um professor de teologia, uma socióloga da religião, um sacerdote e uma jornalista. A escolha de pessoas anônimas, de diferentes espaços e profissões, reside no fato de se querer indagar de que forma elas percebem e lidam com as diferenças entre mulheres e homens no enfrentamento de determinada concepção de religião.

A tentativa de refletir sobre gênero e religião é uma tarefa que pode ser realizada com base em dois eixos: o primeiro se estabelece através da análise da noção de gênero e da noção de religião. $\mathrm{O}$ segundo baseia-se em fragmentos de falas de algumas pessoas que expressaram o seu entendimento em relação a essas categorias.

\section{Noções teóricas sobre religião}

Colocando a questão nesses termos, a religião é uma aposta em algo que não se vê e pode ser considerada a força que faz criar novas opções, mas, por um ato de fé, modifica comportamentos, supera dificuldades de forma inacreditável. Em muitos casos, vira suporte para a vida e a existência. Compõe as experiências vividas que são moldadas pela sociedade e pela cultura. Ela pode ser vista como reforço de normas, impondo controles e formas de viver para homens e mulheres.
A teoria de gênero é relativamente nova e está em constante movimento de crítica, construção e reconstrução desse novo paradigma de conhecimento. A religião de modo geral é estudada, pesquisada e refletida por inúmeros teóricos, porém sempre dentro de uma visão masculina e patriarcal.

Para expor em linhas gerais o que significa cada uma dessas noções, é necessário enfatizar alguns autores que se dedicaram a entender e explicar esses termos. Do ponto de vista de Durozoi e Roussel (1996, p. 406), o termo religião derivaria quer do latim relegere (respeitar e, por extensão, dedicar um culto), quer do verbo religire que significa religar. Portanto, "a religião constitui o traço que une o homem a Deus como à fonte de sua existência”. Com vistas a subsidiar a análise, soma-se a esse entendimento a proposição de Abbagnano (2000, p. 846), que apresenta de modo geral a definição de religião como sendo a crença na garantia sobrenatural de salvação e técnicas destinadas a obter e conservar essa garantia.

Na compreensão de Chauí (1997), a religião é vínculo. Nesse sentido, ela mostra que também é necessário perguntar quais partes devem ser vinculadas. E acrescenta: "o mundo profano e o mundo sagrado, isto é, a Natureza (água, fogo, ar, animais, plantas, astros, pedras, metais, terra, humanos) e as divindades que habitam a Natureza ou um lugar separado da Natureza” (p. 298).

Dando continuidade a essa seqüência de raciocínio, Chauí (1997, p. 300) indica que a "religião tende a ampliar o campo simbólico, mesmo que não transforme todos os seres e objetos em tabus ou intocáveis”. A autora focaliza que "toda religião explica não só a origem da ordem do mundo natural, mas também do mundo humano" (Chauí, 1997, p. 302).

Ampliando a questão, Geertz (1978) analisa a cultura como um sistema de símbolos buscando uma explicação ou uma interpretação. Desta forma, a concepção de cultura do autor é percebida como um polvo com vários tentáculos. Isso o leva a propor a cultura como sistema simbólico no qual é necessário descobrir os significados dos símbolos presentes em qualquer objeto, ato, evento ou relação que sirva de veículo. A cultura como dimensão simbólica reflete, assim, uma totalidade que propicia enxergar e interpretar a religião como um sistema religioso valendo-se de um enfoque de análise cultural, em específico a cultura religiosa, suscitado pelos sistemas simbólicos. Nessa linha de argumentação, Geertz (1978, pp. 104-105) afirma que uma religião é:

(...) um sistema de símbolos que atua para (...) estabelecer poderosas, penetrantes e duradouras disposições e motivações nos homens através da (...) formulação de conceitos de uma ordem de existência geral e (...) vestindo essas concepções com tal aura de fatualidade que (...) as disposições e motivações parecem singularmente realistas.

A preocupação do autor não é encontrar leis universais, mas, com base na interpretação, descobrir os signi- 
ficados dos símbolos. Ele considera que os símbolos são estratégias para abarcar o mundo.

\section{Noções teóricas sobre gênero}

Em consonância com essas argumentações e num esforço de recriar os nexos entre religião e gênero, faz-se necessário enfatizar que essa noção de gênero é entendida como a construção social do modo de ser mulher e o modo de ser homem, que parte da distinção entre o feminino e o masculino, e também subjaz nas teorias evolucionistas. Pode-se mencionar que, desde Darwin, já se marcava essa distinção. Martin e Voorhies (1978, p. 136), ao comentarem a obra de Darwin, The Descent of Man (1874), afirmam que os estereótipos de comportamento masculino e feminino foram extraídos do contexto da filosofia e da tradição popular, quando essas idéias receberam o selo do científico. Os varões - dizem - têm maiores impulsos sexuais e são naturalmente mais afirmativos e competitivos. Pelo contrário, as mulheres não são agressivas, tendem ao cuidado dos pequenos e são focos da hierarquia de domínio dos varões.

Essa dicotomia nem sempre tem a mesma conotação para todas as culturas (Lamas, 1986). Inicialmente, origina-se da diferenciação sexual biológica e, posteriormente, por uma diferenciação social através da divisão social do trabalho.

A categoria de gênero cria-se como resultado dessa distinção biológico-social. Seu uso tem aproximadamente um século, ainda que o termo, como categoria específica nas ciências sociais, só tenha aparecido na década de 1970 (Lamas, 1986, pp. 173-174). No entanto, na multiplicidade de estudos que abordam essa categoria geramse polêmicas, confusões e coincidências.

Alguns autores têm utilizado os termos sexo e gênero como sinônimos, todavia, aqui, estes serão tratados de maneira diferente, conforme o entendimento de Katchadorian (1984), Rubin (1986), Anderson (1985), Sau (1981), Lamas (1986) e outros.

Katchadorian (1984), por exemplo, no seu estudo sobre a sexualidade humana, afirma que a palavra sexo tem sua origem na língua latina sexus e que, definido formalmente, o sexo remete primariamente à divisão de seres orgânicos, identificados como macho e fêmea, e às qualidades que os distinguem. Agrega que um primeiro sentido refere ao macho ou à fêmea como seres determinados por características estruturais e funcionais. Assim, o sexo é um fator biológico que comumente tem uma presença imperativa entre os seres humanos e uma dicotomia que é mutuamente excludente: uma pessoa é macho ou fêmea, e só deve ser uma coisa ou outra. E quanto ao termo gênero, comenta que deriva também da língua latina genus, que significa nascimento ou origem.

Gayle Rubin (1986, p. 97) opta por entender esse processo como um sistema de sexo/gênero e o defi- ne da seguinte maneira: “(...) é o conjunto de disposições pelas quais uma sociedade transforma a sexualidade biológica em produtos da atividade humana, e no qual se satisfazem essas necessidades humanas transformadas".

A proposição de Rubin é fundamental, mesmo não fazendo uma separação taxativa entre essas categorias. Ela desenvolve uma definição mais acabada sobre o sistema sexo/gênero, por meio de uma leitura de Lévi-Strauss e de Freud. Ademais, propõe também o desenvolvimento de uma economia política do sexo. Seu estudo é considerado pioneiro e é ponto de referência para a análise da categoria de gênero.

Uma argumentação que distingue perfeitamente essas categorias é a que expõe Anderson (1985), no sentido de afirmar que sexo é "um atributo biológico, o gênero é a elaboração a partir das diferenças biológicas de papéis, do status, do sistema de repartição de prestígio e prerrogativas, e de uma determinada relação entre pessoas designadas a distintas categorias" (p. 7).

Com base nas leituras desses autores, são reveladas características que podem ser adscritas a uma e outra categoria. Nesse sentido, a distinção entre sexo e gênero pode ser proposta da seguinte forma: o sexo refere-se à identidade biológico-genética e o gênero à identidade designada e adquirida socialmente, isto é, uma construção cultural que implica certas maneiras de manifestarse, sentir e atuar de acordo com o sexo.

Cabe assinalar, também, que a dificuldade em conceituar essas categorias tem provocado o surgimento de outras palavras com conotações similares, tais como: identidade do papel sexual/identidade genérica, papel genérico/identidade sexual e outras mais. Esse fenômeno tem propiciado o aparecimento de uma vasta literatura relacionada com o tema, do qual se destacam, entre outras, a obra de Ortner (1979), composta por vários artigos antropológicos que têm a intenção de apresentar como se configuram a sexualidade e o gênero. Seu ponto de partida são as matrizes sociais e culturais. Nessa direção destacam-se também Katchadorian (1984), Anderson (1985), e Sau (1981).

Lamas (1986), por sua vez, elaborou uma cuidadosa análise sobre a categoria de gênero apresentando dados históricos relacionados com essa categoria, bem como os diversos estudos realizados até este momento sobre o tema. Também aborda os debates mais significativos dessa problemática teórica, como o viés androcêntrico da antropologia, a definição da categoria gênero, a oposição natureza/cultura, em que retoma Sherry Ortner (1979) e, por fim, analisa as instâncias que conformam o gênero. Segundo ela, estão articuladas da seguinte forma:

a) A designação (rótulo, atribuição) de gênero: Está relacionada com o momento em que nasce o bebê, tomando-se por base a aparência externa dos genitais. Ainda quando a autora não toma em conta outro elemento, cabe 
aclarar que isso, hoje, já é um fator relativo dado que, com os avanços tecnológicos, pode-se saber o sexo antes do nascimento, através da ultra-sonografia;

b) A identidade de gênero: A identidade de gênero se estabelece mais ou menos na mesma idade em que o infante adquire a linguagem (entre dois e três anos) e é anterior a um conhecimento sobre a diferença anatômica entre os sexos;

c) O papel (rol de gênero): O papel, ou rol de gênero, forma-se com o conjunto de normas e prescrições que ditam a sociedade e a cultura sobre o comportamento feminino ou masculino. Ainda que existam variações de acordo com a cultura, a classe social, o grupo étnico e até o aspecto geracional das pessoas, pode-se sustentar uma divisão básica que corresponde à divisão sexual do trabalho mais primitiva: as mulheres têm os filhos e, portanto, cuidam deles; o feminino é o maternal, o doméstico contraposto com o masculino como o público. A dicotomia masculino-feminino, em suas variações culturais, tipo o Yang e o Ying, estabelecem estereótipos, muitas vezes rígidos, que condicionam os papéis limitando as potencialidades humanas das pessoas ao potencializar ou reprimir os comportamentos no que concerne serem eles adequados ao gênero.

Da leitura do artigo de Lamas (1986, p. 188), depreende-se que as instâncias fundamentais que conformam o gênero, são a designação de gênero, a identidade de gênero e o papel de gênero. As características intrínsecas a esse modelo podem ser estudadas em qualquer sociedade, independentemente do grau de sua complexidade.

Nesta rápida revisão da literatura pontuou-se o que se produziu nessas duas décadas sobre a categoria de gênero nas ciências sociais e especialmente na antropologia. Há que se considerar, contudo, outros autores que trabalharam essa categoria entre os anos 1985 a 1990, e o percurso por eles realizado, como se segue.

Heilborn (1992, p. 98) a concebe como "a distinção entre atributos culturais alocados a cada um dos sexos e a dimensão biológica dos seres humanos”. Scott (1995, p. 86) conceitua gênero da seguinte forma: “... é um elemento constitutivo de relações sociais baseadas nas diferenças percebidas entre os sexos sendo que o gênero é uma forma primária de dar significado às relações de poder”. Para Suely Kofes (1993, pp. 19-30.), "gênero seria um instrumento que mapeia um campo específico de distinções, aquele cujos referentes falam da distinção sexual".

Com base nesses referenciais, pode-se afirmar que a categoria de análise - gênero - está cada vez mais presente na produção do saber e de forma interdisciplinar. Há muita polêmica quanto ao seu uso e aplicação, assim como existem vários enfoques sobre a mesma. Os diversos usos da categoria enriquecem a dinâmica do conhecimento, contribuindo com o avanço das análises e explicações dessa temática. Todavia, ainda sobre a categoria de gênero, é importante frisar que esta revolucionou os estudos feministas e que seu uso expandiu gerando conflitos e desafios na construção do novo paradigma.

Para Marta Lamas (2000, p. 13),

o grande êxito do feminismo foi ter conseguido modificar não somente a perspectiva política com que se abordava o conflito nas relações mulher-homem, mas também transformar o paradigma utilizado para explicá-lo. O novo conceito gênero permitiu a compreensão de que não é a anatomia que posiciona mulheres e homens, em âmbitos e hierarquias distintos, e sim a simbolização que as sociedades fazem dela.

Da leitura de Lamas é possível afirmar que sua contribuição, ao explicitar como se estabelece a diferença de gênero, é impar. Ela sinaliza que a eficácia do feminismo é consolidada na forma como se aborda o conflito estabelecido nas relações mulher-homem. Esse conflito surge desde que um bebê é concebido. Toda atmosfera criada em torno do futuro ser, assim como toda carga cultural simbólica do que é ser feminino e masculino, é nele introjetado durante e depois da gravidez.

Dessa forma, o processo educativo ocorre com base em comportamentos relacionados com os papéis que a sociedade designa para cada sexo. Os atributos destinados ao feminino e ao masculino são construídos socialmente através de objetos, gestos, falas, presentes, escolha do nome, cores de enxoval e brinquedos, etc. Ao constatar essa situação, a teoria feminista transforma 0 paradigma biológico-social utilizado para explicar esses papéis desempenhados por homens e mulheres, fornecendo instrumentos capazes de possibilitar uma desconstrução e reconstrução da análise de gênero na perspectiva cultural.

\section{Gênero e religião na perspectiva da redescrição}

Prosseguindo, com o exercício de reflexão, apresentam-se, a seguir, alguns relatos que possibilitam articular gênero e religião. A primeira pessoa abordada foi um professor de teologia que prontamente se dispôs a responder sobre qual era seu entendimento a respeito de gênero e religião.

No que se refere à primeira concepção, ele afirmou que gênero é "o estudo que permite estabelecer uma relação equilibrada e própria entre os sexos. $\mathrm{O}$ feminino frente ao masculino e o masculino frente ao feminino".

Ao se analisar a definição do professor, procurando estabelecer uma conexão com a análise de gênero desenvolvida anteriormente, nota-se uma imprecisão e uma contradição no se refere à concepção apresentada porque, contrariamente ao que se afirmou, os estudos de gênero estão voltados para o aprofundamento da construção e desconstrução dos papéis masculino e fe- 
minino como um elemento constitutivo de relações sociais baseadas nas diferenças percebidas entre os sexos, sendo que o gênero é uma forma primária de dar significado às relações de poder e não um mecanismo que permite estabelecer uma relação equilibrada e própria entre os sexos. Desse ponto de vista, a categoria indica justamente o contrário. O uso dessa noção dá visibilidade à construção social do modo de ser mulher e de ser homem com base na distinção entre o feminino e o masculino. Portanto, valer dessa análise como explicação das diferenças e desigualdades sociais entre os gêneros favorece também a desconstrução indicando que o conflito nas relações mulher-homem deve ser visto com base no paradigma biológico-social empregado para explicar essas diferenças nos papéis desempenhados por homens e mulheres.

Com relação à religião, o professor sinaliza:

este termo não é uma criação da língua portuguesa, existe há milhares de anos e em sua significação mais tranqüila estimula os indivíduos à busca de uma re-ligação física/ espiritual com a realidade do mistério que envolve o existir humano: como sua origem e o seu fim, como a morte, a dor, o sofrimento, a alegria, o silêncio lembrando-nos apenas de alguns destes mistérios.

A compreensão de religião desse professor não difere muito do que já foi apontado por alguns autores ao longo desse texto. É necessário mencionar que sua formulação de gênero e religião se deu de forma desvinculada uma da outra. No relato não aparece, sequer, a tentativa de articulação das mesmas. Gênero e religião são ainda concepções sem uma relação precisa e necessitam ser buriladas.

Considerando tudo isso, registra-se a fala de uma socióloga da religião que expõe sua compreensão sobre essas noções:

Na trajetória do cristianismo ou do judeu-cristianismo, ao enfatizar as figuras sagradas dentro do mundo masculino (Deus, Jesus, Abraão, Moisés, Josué...) contribui para que as mulheres se entendam como menos sagradas e não escolhidas por Deus para serem suas representantes; pior ainda, são entendidas como responsáveis pelas dores do mundo (Eva). Isso gera nas mulheres que crêem numa baixa auto-estima um permanente senso de culpa e de necessidade de que eles (os "bons" e "escolhidos" por Deus) as ajudem a não pecar e a conseguir a salvação. Nos homens ocorre o processo oposto. Isso resulta numa relação desigual de gênero como sendo da vontade de Deus.

Pode-se observar de acordo com a citação acima que a compreensão da socióloga sobre essas duas noções tem como parâmetro justamente a marca de gênero, ou seja, o masculino e o feminino na conformação cultural e social dos papéis desempenhados por mulheres e homens de maneira desigual no que se refere à experiência do sagrado.
Diferentemente do professor, ela faz um recorte utilizando a questão de gênero para explicitar sua visão dos papéis masculinos e femininos no campo religioso mostrando como o masculino se torna o intermediário na experiência com Deus.

O terceiro relato é o de um padre e pode ser entendido como uma acepção mais geral na qual ele argumenta:

Penso que a relação entre religião e gênero está situada, na atualidade, num contexto de revisão das atitudes das religiões considerando as relações mulher/homem. Diria que estamos carentes de uma hermenêutica que possibilite a revisão de textos sagrados e palavras mal ditas no decorrer da nossa história. O papel desta relação gênero/religião consiste, então, numa abertura da mente e do coração para se pensar diferente os encontros entre o ser feminino e o masculino.

Nesse fragmento, é possível identificar nas entrelinhas que se tem clareza da construção social dos papéis desempenhados por mulheres e homens na configuração e vivência de uma religião. Constata-se também a disposição para perceber a necessidade de desconstrução dos referidos papéis.

A última fala é a de uma jornalista e professora que manifesta sua concepção da relação entre religião e gênero apontando elementos importantes para a compreensão de gênero como uma experiência não institucionalizada e da religião como instituição.

Gênero e religião é um tema que me remete para o contraditório. Ao mesmo tempo em que a instituição religiosa aponta valores morais que impõem padrões opressivos às mulheres e repressivos a todos (a sexualidade, por exemplo, é um campo bastante fértil para a opressão e controle das instituições religiosas), a religião em si mesma se revela como uma necessidade humana de transcendência: a espiritualidade para além do concreto e da realidade pura. É como se fosse um elemento gerador de novas energias (boas e ruins), capaz de interferir na criatividade e na capacidade humana de conviver com o contraditório e ou com o inexplicável. Não tenho dúvida que homens e mulheres vivenciam a religiosidade de forma diferente, impregnados de sua condição sexual, cultural, social etc. Acho que é sobre isso que os estudos sobre gênero e religião devem se debruçar: como homens e mulheres vivenciam a experiência religiosa?

Referenciada pela noção de gênero, ela afirma: "Não tenho dúvida que homens e mulheres vivenciam a religiosidade de forma diferente, impregnados de sua condição sexual, cultural, social, etc”. De uma forma quase filosófica ela responde a questão devolvendo e recolocando de novo, de outra maneira, a pergunta com a qual foi interpelada: "Como homens e mulheres vivenciam a experiência religiosa?” A recolocação do problema abordado instiga a continuar conversando sobre o assunto, a revisar conceitos, idéias e as referências construídas e estabelecidas. 
Sem a pretensão de concluir, dando respostas prontas e acabadas a respeito dessa relação entre gênero e religião, faz-se oportuno insistir e retomar alguns elementos que foram enunciados nessa análise e que permitem recuperar a capacidade criativa de ver, pensar, refletir e analisar gênero e religião por um ângulo novo. Primeiro, a aposta na redescrição desatou os nós, teceu uma rede de significados e forjou um caminho no qual é possível encontrar ferramentas que facilitem a criação de novas expressões, novos vocabulários e também sejam capazes de inventar uma nova versão de nós mesmos. Isso é o que aconselha a filosofia pragmatista.

É no exercício de tecer a rede, de esculpir o mármore, lapidar a palavra para dar forma a uma invenção que se revela em metáforas que unem os fios para construir elos e recriar nexos entre o pragmatismo como teoria $a d$ hoc e o recontar uma história que contempla a relação entre gênero e religião. Os argumentos podem ser tecidos ou rebordados pelos significados do que se entende e se vivencia nas experiências religiosas de mulheres e homens compondo um novo desenho.

O recurso, as estratégias adotadas neste texto para abordar o assunto revelaram trilhas que aproximam a noção do sagrado e podem encontrar um ponto convergente com o que expõe Marilena Chauí (1997, p. 297) quando argumenta: "o sagrado é a experiência simbólica da diferença entre os seres, da superioridade de alguns sobre outros, do poderio de alguns sobre outros, superioridade e poder sentidos como espantosos, misteriosos, desejados e temidos".

A outra pegada importante é a que se delineia com o último relato no que se refere ao escancaramento do controle das instituições religiosas sobre a sexualidade e os corpos das mulheres. Esse tema é crucial, polêmico e deve ser enfrentado pelas igrejas e pelo movimento feminista. O desafio está colocado.

Na ilação de tudo o que foi elaborado até o momento, o emprego dos fragmentos de fala registrados é a apropriação de uma ferramenta que desencadeou um processo: apontar caminhos e descobrir novas formas para analisar a questão.

Em suma, quando se acha a metáfora, seu uso de acordo com o que já foi mencionado modifica o comportamento lingüístico. Neste sentido, ao alterar esse comportamento, provocam-se mudanças. Acredita-se que o debruçar sobre as experiências de mulheres e homens signifique e resulte em novas possibilidades de construção de uma versão melhor dos gêneros na relação com a religião. Eis aí uma aposta.

\section{Referências Bibliográficas}

Abbagnano, N. (2000). Dicionário de filosofia. São Paulo: Martins Fontes.
Anderson, J. (1985). De los estudios de la mujer al estudio de género: hacia la renovación de la antropología peruana. Mimeo, pp.7-15.

Chauí, M. (1997). Convite à filosofia. São Paulo, São Paulo: Ática.

Costa, A. de O. \& Bruschini, C. (Orgs.). (1992). Uma questão de gênero. Rio de Janeiro: Rosa dos Tempos / São Paulo: Fundação Carlos Chagas.

Costa, A. A. A. \& Sardenberg, C.M.B. (1994). Teoria e práxis feministas na academia. Os núcleos de estudos sobre a mulher nas universidades brasileiras. In: Estudos feministas. Número Especial $/ 2^{\circ}$ Sem. Rio de Janeiro: CIEC/ECO/UFRJ, pp. $387-400$.

Durozoi, G. \& Roussel, A. (1996). Dicionário de filosofia. Campinas: Papirus.

Urlani, L. M. T. (1992). Fruto proibido. um olhar sobre a mulher. São Paulo: Pioneira/ Uniceb.

Geertz, C. (1978). A interpretação das culturas. Rio de Janeiro: Zahar.

Ghiraldelli Jr, P. (1999). Richard Rorty. A filosofia do novo mundo em busca de mundos novos. Petrópolis: Vozes.

Ghiraldelli Jr, P. (2003). Introdução à filosofia. Textos básicos Filosofia e Ciências humanas. São Paulo: Manole.

Heilborn, M. L. (1992). Fazendo gênero? A antropologia da mulher no Brasil. In: A. de O Costa, \& C. Bruschini, (Orgs). Uma questão de gênero (pp. 93-125). Rio de Janeiro: Rosa dos Tempos / São Paulo: Fundação Carlos Chagas.

Katchadorian, H. (1993). La sexualidad humana un estudio comparativo de su evolución. México: Fondo de Cultura Económica.

Kofes, S. (1993). Categorias analítica e empírica: gênero e mulher: disjunções, conjunções e mediações. Cadernos Pagu. Nr. 1; pp. 19-30.

Lamas, M. (1986). La antropologia feminista y la categoria género. Nueva Antropologia, vol.VIII, n. 30, México, pp. 173-198

Lamas, M. (2000). Gênero: Os conflitos e desafios do novo paradigma. Proposta, n. 84/85, Março/Agosto, pp. 12-25.

Martin, K. M. \& Voorhies, B. (1978). La mujer: un enfoque antropológico. Barcelona: Anagrama.

Ortner, S. (1979). Es la mujer con respecto el hombre lo que la naturaleza con respecto a la cultura. Antropología y feminismo. Harris, O; Young. (Comp.) Barcelona: Anagrama, pp. 109-131.

Rubin, G. (1986). El tráfico de mujeres: notas sobre la economia política del sexo. Nueva antropología, vol.VIII, n.30, México, pp. 95-145.

Ruether, R.R. (1993). Sexismo e religião. São Leopoldo, RS: Sinodal. 
Sau, V. (1981). Un diccionario ideológico feminista. Barcelona: Icaria.

Scott, J. (1995). Gênero: Uma categoria útil de análise histórica. Educação \& Realidade. Porto Alegre.Vol.20, Nr.02, pp. 71-99.

Maria José Pereira Rocha - Possui graduação em Pedagogia pela Universidade Federal de Goiás (1980), Mestrado em Antropologia Social pela Escuela Nacional de Antropologia y História (México, 1990) e Doutorado em Educação pela Universidade Católica de Goiás/Universidade Estadual de São Paulo - Marília (2002). Atualmente é professora Adjunta I da Universidade Católica de Goiás (UCG); Pesquisadora no Programa Interdisciplinar da Mulher - Estudos e Pesquisas (Pimep), no Centro de Estudos em Filosofia Americana e no Núcleo de Investigação de Gênero (NIG) da UCG. Endereço para correspondência: Rua 233, ${ }^{\circ} 161$, Ed. $1^{\circ}$ de Maio, Ap.104 (Setor Universitário), Goiânia, CEP 74605-120. Email. maze@cultura.com.br

Recebido em 10.05 .08

Primeira Decisão Editorial em 25.08.08

Aceito em 20.09.08 